Acta Technologica Agriculturae 1

Nitra, Slovaca Universitas Agriculturae Nitriae, 2018, pp. 38-43

\title{
LEVEL REDUCTION OF OUTPUT NOISE OF REFERENCE VOLTAGE SOURCES
}

\author{
Sergey BONDAR ${ }^{1}$, Maria ZHAVORONKOVA ${ }^{1}$, Aleksandr VOSTRUKHIN ${ }^{2}$, \\ Elena VAKHTINA ${ }^{1 *}$, Elena ZORINA ${ }^{1}$ \\ ${ }^{1}$ Stavropol State Agrarian University, Russia \\ ${ }^{2}$ Stavropol Technological Institute of Service, Russia
}

\begin{abstract}
Technologies for processing of digital signals find broad application in all spheres of the human activity, including agriculture. Further perfecting of these technologies is related to increasing of resolving power in analogue-to-digital and digital-to-analogue converters, requiring the improvement of quality indicator of the reference voltage sources such as noise level. This paper presents the possibilities for level reduction of output noise of the reference voltage sources. Circuit solutions of the single-stage and twostage, unipolar and bipolar low-noise sources of stable voltage of direct current produced on the basis of standard integral chips of voltage stabilizers are observed. The proposed circuit solutions provide reduction of output noise level of the reference voltage sources to the level of intrinsic noise of the operational amplifiers, which are part of the developed devices. It should be emphasized that single-stage unipolar low-noise sources of stable voltage of direct current are characteristic by the inversion of output voltage polarity that takes place in accordance with the polarity of output voltage of voltage stabilizer integral chip.
\end{abstract}

Keywords: voltage stabilizer; noise component; phase shift; time constant; frequency band

The precision reference voltage sources (RVS) are broadly used. However, their application is usually needed in creation of the analogue-to-digital and digital-to-analogue converters (ADC and DAC), which are a part of an inventory of electric devices, control systems power supply, automated process control systems of both production and agricultural objects (Cviklovič et al., 2016; Hsu et al., 2013).

The considerable proportion of integrated circuits (ICs) of the integrated voltage regulator (IVR) (MAX872, AD584, ARD292) is characteristic by production of a high level of intrinsic noise that significantly limits their application field as the RVS of ADC and DAC.

The following methods for a reference voltage production are known:

a) a method that implements the operations of stabilizing the output voltage and then filtering it (Horowitz and Hill, 2015);

b) a method based on a low-noise voltage reference that represents a combined cycle system (Neidorff and Bedford, 1989);

c) on the basis of the reference voltage source SU 421002A (Lantsov, 1974), which represents a closed loop system.

The disadvantage of all these methods lies in a production of significant noise level. Recently, solutionsfor the RVSconstruction on the basis of single-crystal programmable systems, microcontrollers (Vostrukhin, 2013), are being proposed. However, questions of an assessment of a noise level remain open.

This paper investigates the devices providing the reduction of the RVS output noise level produced on the basis of standard ICs of IVRs.

\section{Material and methods}

Single-stage noise reduction

Single-stage noise reduction (Bondar, 2010a) requires the performance of the following operations:

1. allotment of a noise (variable) component of RVS output voltage;

2. compensation of a noise (variable) component in RVS output voltage.

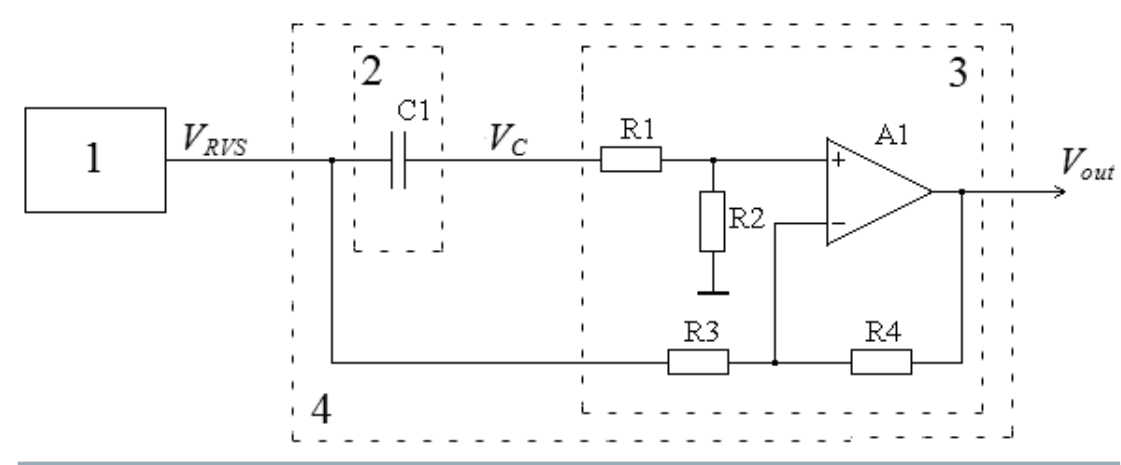

Fig. 1 Scheme for single-stage noise reduction

The scheme contains: RVS [1]; decoupling capacitor [2]; subtractor [3]; converter [4]. The allocated noise component, by means of the decoupling capacitor [2] (condenser C1) and an output signal, the RVS [1] arrive on entrances of the subtractor [3] which is carrying out the compensation (suppression) of a noise component 
The scheme describing how the device performs singlestage noise reduction is shown in Fig. 1.

The suppression extent of a noise component is considerably defined by a time constant $\tau_{\text {con }}$ of the highpass filter of the converter [4] formed by the chain C1, R1, $\mathrm{R} 2$, as well as by a phase shift $\varphi_{\text {con }}(\omega)$, where $\omega$ - the current frequency. The allocated noise component will be defined by the following dependence:

$$
\begin{gathered}
\varphi_{\text {con }}(\omega)=\frac{\pi}{2}-\operatorname{arctg}\left(\omega \cdot \tau_{\text {con }}\right) \\
\tau_{\text {con }}=C_{1} \cdot\left(R_{1}+R_{2}\right)
\end{gathered}
$$

where:

$C_{1} \quad$ - the capacity of the decoupling condenser [2]

$R_{1}, R_{2}$ - the resistance of R1, R2 resistors of the subtractor [3]

$\tau_{\text {con }} \quad$ - time constant of a RVS [1] chain

$$
\tau_{\text {RVS }}=C_{1} \cdot R_{\text {RVSout }}
$$

where:

$R_{\text {RVSout }}$ - the output resistance of RVS [1]

At the same time, conditions are also imposed on $\tau_{\text {con' }}$ $\tau_{R V S}, R_{1}$ and $R_{2}$ :

$$
\left.\begin{array}{c}
\tau_{\text {con }} \rightarrow \infty \\
\tau_{\text {con }} \rightarrow 0 \\
R_{1}=R_{2}=R_{3}=R_{4}
\end{array}\right\}
$$

where:

$R_{3}, R_{4}$ - the resistance of $\mathrm{R} 3, \mathrm{R} 4$ resistors of the subtractor [3]

Since condition (4) (namely: $\tau_{\text {con }} \rightarrow \infty$ ) is not technically realizable (increase in face values of elements will lead to unstable operation of the operational amplifier (Op-amp) A1 for the purpose of increase $\tau_{\text {con }}$ ), there will be an inexact suppression of a noise component (in the area of infra-low frequencies). In other words, there will be a narrow-band compensation of a noise component of the RVS output tension due to the arising phase shift. Especially the model operation of single-stage reduction in RVS noise in case of usage of elements with marginal parameters: $C_{1}=1 \mu \mathrm{F}$; $R_{1}=R_{2}=R_{3}=R_{4}=500 \mathrm{k} \Omega ;\left(\tau_{\text {con }}=1 \mathrm{c}\right)$ showed the frequency dependence of both phase shift $\varphi_{1 d}(\omega)$ and noise reduction coefficient $K_{1 d}(\omega)$, as shown in Table 1.

The instantaneous value of noise output voltage $V_{1 d}$ of the device performing the RVS single-stage noise reduction is defined by expression:

$$
V_{1 d}(\omega) \approx \frac{V_{R V S}(\omega)}{K_{1 d}(\omega)}+V_{A 1}(\omega)
$$

where:

$V_{1 d} \quad$ - instantaneous noise value of the RVS in singlestage noise reduction

$V_{R V S}$ - instantaneous noise value of the RVS

$V_{A 1} \quad$ - instantaneous noise value of Op-amp A1 of subtractor [3]

It is possible to reduce the RVS noise when using Op-amp A 1 IC - OP07C with a $0.38 \mu \mathrm{V}$ peak-to-peak equivalent input noise voltage in a frequency band $0.1 \div 10 \mathrm{~Hz}$ (Table 2 ).

This apparatus is to change the polarity of the stabilized voltage (the output voltages of the device and RVS [1] have opposite signs).

The disadvantage of the single-stage noise reduction devices is related to the fact that noise component produces a significant noise level within the infra-low-frequency range and high demands imposed on a subtractor chain time constant (ideally, $\tau_{\text {con }}>>1 \mathrm{c}$ ).

One of possible solutions for the elimination of these shortcomings lies in transition from the technology of single-stage noise reduction to the two-stage technology.

\section{Two-stage noise reduction}

The two-stage solution (Zhavoronkova and Bondar, 2012) requires the performance of the following operations:

1. conversion of a spectrum of output voltage of RVS;

2. isolating of a noise (variable) component of the converted

\begin{tabular}{|c|c|c|c|c|c|}
\hline \multirow[t]{3}{*}{ Type of IVR } & \multirow{3}{*}{$\begin{array}{l}\text { Output noise voltage of IVR in a frequency } \\
\text { band } 0.1 \div 10 \mathrm{~Hz} \text { in } \mu \mathrm{V} \text { p-p }\end{array}$} & \multicolumn{4}{|c|}{ Output noise voltage of the device in $\mu \mathrm{V}$ p-p } \\
\hline & & \multicolumn{4}{|c|}{ frequency in $\mathrm{Hz}$} \\
\hline & & 0.1 & 0.2 & 1 & 10 \\
\hline MAX872 & 60 & 51.2 & 37.6 & 9.8 & 1.4 \\
\hline AD584 & 50 & 42.8 & 31.4 & 8.2 & 1.2 \\
\hline ARD292 & 12 & 10.6 & 7.8 & 2.3 & 0.6 \\
\hline
\end{tabular}
output voltage;

Table 1 Phase shift and noise suppression coefficient

\begin{tabular}{|l||c|c|c|c|c|}
\hline$\frac{\omega}{2 \pi}$ in $\mathbf{H z}$ & 0.1 & 0.2 & 1 & 10 & 100 \\
\hline$\varphi_{1 d}(\omega)$ in degrees & 57.858 & 38.512 & 9.048 & 0.912 & 0.091 \\
\hline$K_{1 d}(\omega)$ & 1.18 & 1.61 & 6.4 & 64 & 640 \\
\hline
\end{tabular}

Table 2 Output noise voltage of the device 


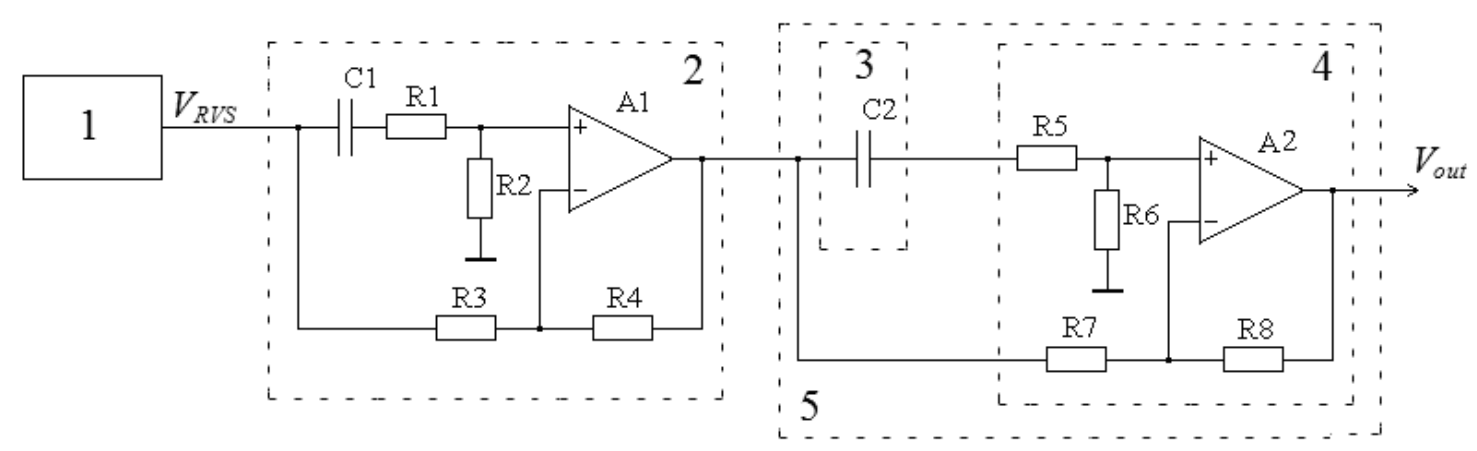

Fig. 2 Scheme for two-stage noise reduction

The scheme contains: RVS [1]; converter [2]; decoupling capacitor [3]; subtractor [4]; converter [5]

3. compensation of the noise (variable) component of output voltage.

The scheme of the device performing two-stage noise reduction is shown in Fig. 2.

For example, when using MAX872, the RVS output signal contains a noise component, the lower threshold of a spectral distribution of which corresponds to the region of infra-low frequencies (about $0.1 \mathrm{~Hz}$ ). Converter [2] reduces the noise level, but, first of all, narrows a spectral band of a noise component of RVS [1] signal: the lower bound is increasing with the decline of the upper bound.

This effect is described by an algorithm of the converter [2] operation:

1. The group delay $\tau_{d e l}$ of the bending-around noise component of the RVS [1] signal arising due to passing of the signal through the filter of high frequencies formed by the $\mathrm{C} 1$ condenser and $\mathrm{R} 1, \mathrm{R} 2$ resistors:

$$
\tau_{d e l}(\omega)=\frac{d \varphi_{2}(\omega)}{d \omega}=\frac{\tau_{\text {con2 }}}{\left(\tau_{\text {con2 } 2} \cdot \omega\right)^{2}}
$$

where:

- the phase shift introduced by the high-pass filter of converter [2]

$$
\varphi_{\text {con } 2}(\omega)=\frac{\pi}{2}-\operatorname{arctg}\left(\omega \cdot \tau_{\text {con } 2}\right)
$$

where:

$\tau_{\text {con2 }}$ - time constant of the high-pass filter of converter 2

$$
\tau_{\text {con } 2}=C_{1}\left(R_{1}+R_{2}\right)
$$

where:

$C_{1}$ - capacitance of the isolating capacitor $C_{1}$ of converter 2

$R_{1}, R_{2}-$ resistance of $\mathrm{R} 1, \mathrm{R} 2$ resistors of converter 2

2. Subtraction of the noise component from the signal of RVS [1] delayed envelope.

At the same time, the following condition is superimposed on the resistance value of resistors of converter [2]:

$$
R_{1}=R_{2}=R_{3}=R_{4}
$$

where:

$R_{3}, R_{4}$ - resistance of $\mathrm{R} 3, \mathrm{R} 4$ resistors of converter [2]

Due to the non-periodicity and non-sinusoidal form of the envelope of the RVS [1] signal noise component and the dependence of the group delay from the frequency,

$$
\left.\begin{array}{rl}
\tau_{d e l}(\omega \rightarrow 0) & \rightarrow \infty \\
\tau_{d e l}(\omega \rightarrow \infty) & \rightarrow 0
\end{array}\right\}
$$

In this manner, infra-low-frequency and low-frequency fragments of the envelope of the noise component will be subjected to fragmentation and partial suppression, and high-frequency components to complete suppression.

The noise component of the signal of converter [2] is treated with the help of the capacitor C2 of decoupling capacitor [3].

The allocated noise component and an output signal of converter [2] reach inputs of subtractor [4], which compensates (suppression of) the noise component.

The following condition is imposed on the resistance of subtractor [4]:

$$
R_{5}=R_{6}=R_{7}=R_{8}
$$

where:

$R_{5}, R_{6}, R_{7}, R_{8}$ - resistance of $\mathrm{R} 5, \mathrm{R} 6, \mathrm{R} 7, \mathrm{R} 8$ resistors of subtractor [4]

The time constant $\tau_{5}$ of the high-pass filter circuit of converter [5] formed by the chain C2, R5, R6 is defined by the following expression:

$$
\tau_{\text {con5 }}=C_{2} \cdot\left(R_{5}+R_{6}\right)
$$

where:

$C_{2} \quad$ - capacity of decoupling capacitor [3]

The conducted research has shown (Table 3) that when using the RVS [1] of IVR of the MAX872, AD584, ARD292 series as Op-amp A1 and A2 IC of OP07C with passive elements:

1. $C=0.25 \mu \mathrm{F} ; R=500 \mathrm{k} \Omega ;\left(\tau_{\text {con } 2}=\tau_{\text {con } 5}=0.25 \mathrm{~s}\right)$, the instantaneous noise value of the device performing twostage noise reduction $V_{2 d}$ at frequencies of higher than 10 $\mathrm{Hz}$ is determined by the relation: 


$$
V_{2 d} \approx V_{A 2}
$$

where:

$V_{2 d}$ - instantaneous noise value of the device with two-stage noise reduction

$V_{A 2} \quad$ - instantaneous noise value of the Op-amp A2 of subtractor [4], approximately $0.38 \mu \mathrm{V}$ peak-to-peak

2. $C=0.82 \mu \mathrm{F} ; R=500 \mathrm{k} \Omega ;\left(\tau_{\text {con } 2}=\tau_{\text {con } 5}\right.$ $=0.82 \mathrm{~s})$, the instantaneous noise value of the device corresponds with the noise level of device performing a single-stage noise suppression when $\mathrm{C}=1 \mu \mathrm{F}\left(\tau_{\text {con }}=\right.$ $1 \mathrm{~s})$, resulting from the capacity of the used capacitors (the lower, the better); according to Eq. (14), $V=1.22$ in a frequency band $0.1 \div 10 \mathrm{~Hz}$.

$$
V=\left.\frac{C_{1 d}}{C_{2 d}}\right|_{1 d}=K_{2 d}
$$

where:

$C_{1 d}, C_{2 d}$ - capacities of capacitors in single-stage and two-stage noise reduction

$K_{1 d}$ - coefficient of noise suppression in single-stage noise reduction

$K_{2 d}$ - resultant coefficient of noise suppression in two-stage noise reduction

Creation of a reference voltage with a two-stage noise reduction, taking into account the given level of noise reduction, implies a significant reduction in the requirements for the time constant of noise reduction steps (converters).

\section{Bipolar single-stage noise reduction}

The bipolar single-stage method (Bondar, 2010b) requires the performance of the following operations:
1. separation of a noise (variable) component of the RVS non-inverted output voltage;

2. compensation of a noise (variable) component of the RVS non-inverted output voltage;

3. inverting of the RVS output voltage;

4. separation of a noise (variable) component of the RVS inverted output voltage;

5. compensation of a noise (variable) component of the RVS inverted output voltage.

The circuit of the device for formation of a bipolar reference voltage with a single-stage noise reduction is shown in Fig. 3.

It should be emphasized that circuit solutions for realization of blocks 2, 5 (Fig. 3) and block 2 of singlestage noise reduction device (Fig. 1), as well as blocks 3, 6 (Fig. 3) and block 3 (Fig. 1) are identical. The main feature of the scheme shown in Fig. 3 is the inverter [4], with elements upon which condition (15) is imposed:

$$
R_{6}=R_{7}
$$

where:

$R_{6}, R_{7}$ - resistance of $\mathrm{R} 6, \mathrm{R} 7$ resistors of inverter [4]

Due to the identical parameters of the circuit elements in single stage noise reduction and bipolar single stage noise reduction (Figs 1 and 3 ), the degree of noise reduction in the RVS is the same in both cases.

\section{Bipolar two-stage noise reduction}

This solution (Zhavoronkova and Bondar, 2014) requires performing the following operations:

1. conversion of a spectrum of the RVS non-inverted output voltage;

2. separation of the noise (variable) component of the non-inverted transformed output voltage;

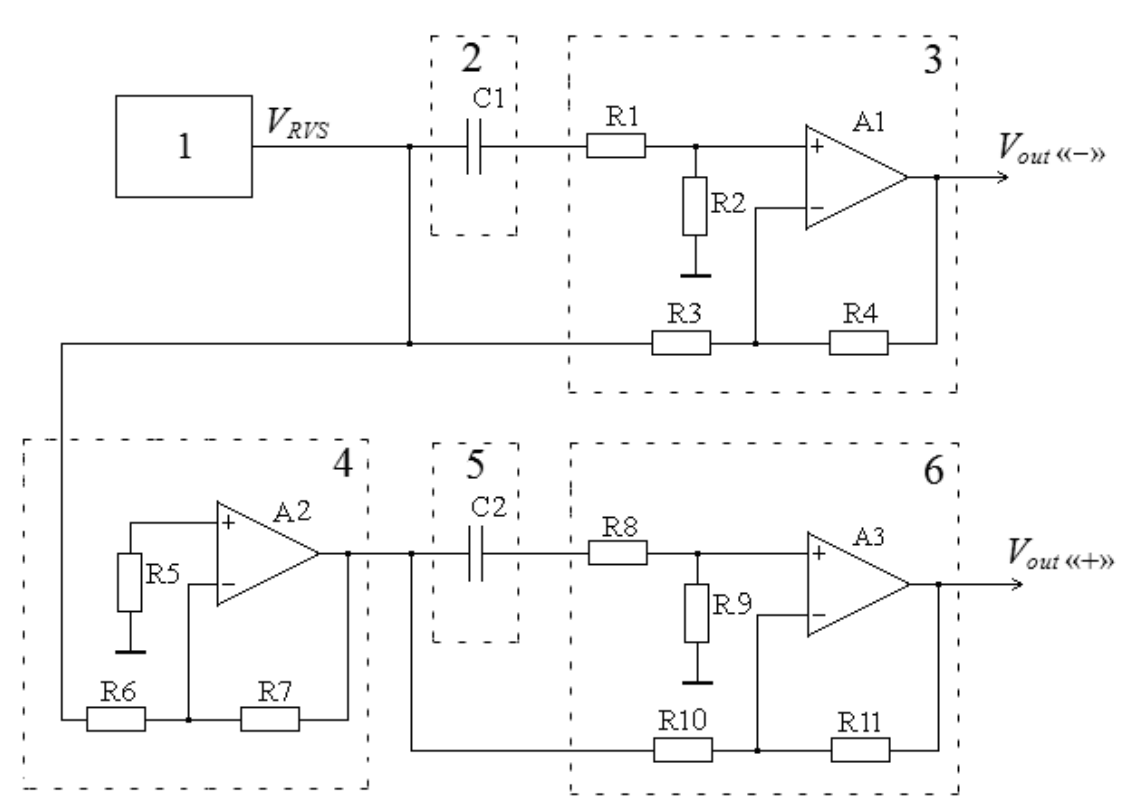

Fig. 3 Scheme for bipolar single-stage noise reduction

The scheme contains: RVS [1]; decoupling capacitors [2] and [5]; subtractors [3] and [6]; inverter [4]

Table 3 Output noise voltage of the device

\begin{tabular}{|l||c|c|c|c|c|}
\hline \multirow{2}{*}{ Type of IVR } & $\begin{array}{c}\text { Output noise voltage of IVR in a frequency } \\
\text { band } \mathbf{0 . 1} \div \mathbf{1 0} \mathbf{~ H z ~ i n ~} \mu \mathbf{V} \text { p-p }\end{array}$ & \multicolumn{4}{|c|}{ Output noise voltage of the device in $\mu \mathbf{V}$ p-p } \\
\cline { 3 - 6 } & & \multicolumn{4}{|c|}{ frequency in $\mathbf{~ H z}$} \\
\hline \hline MAX872 & 60 & $\mathbf{0 . 1}$ & $\mathbf{0 . 2}$ & $\mathbf{1}$ & $\mathbf{1 0}$ \\
\hline AD584 & 50 & 36.2 & 23.5 & 1.8 & 0.394 \\
\hline ARD292 & 12 & 9 & 20 & 1.6 & 0.392 \\
\hline
\end{tabular}




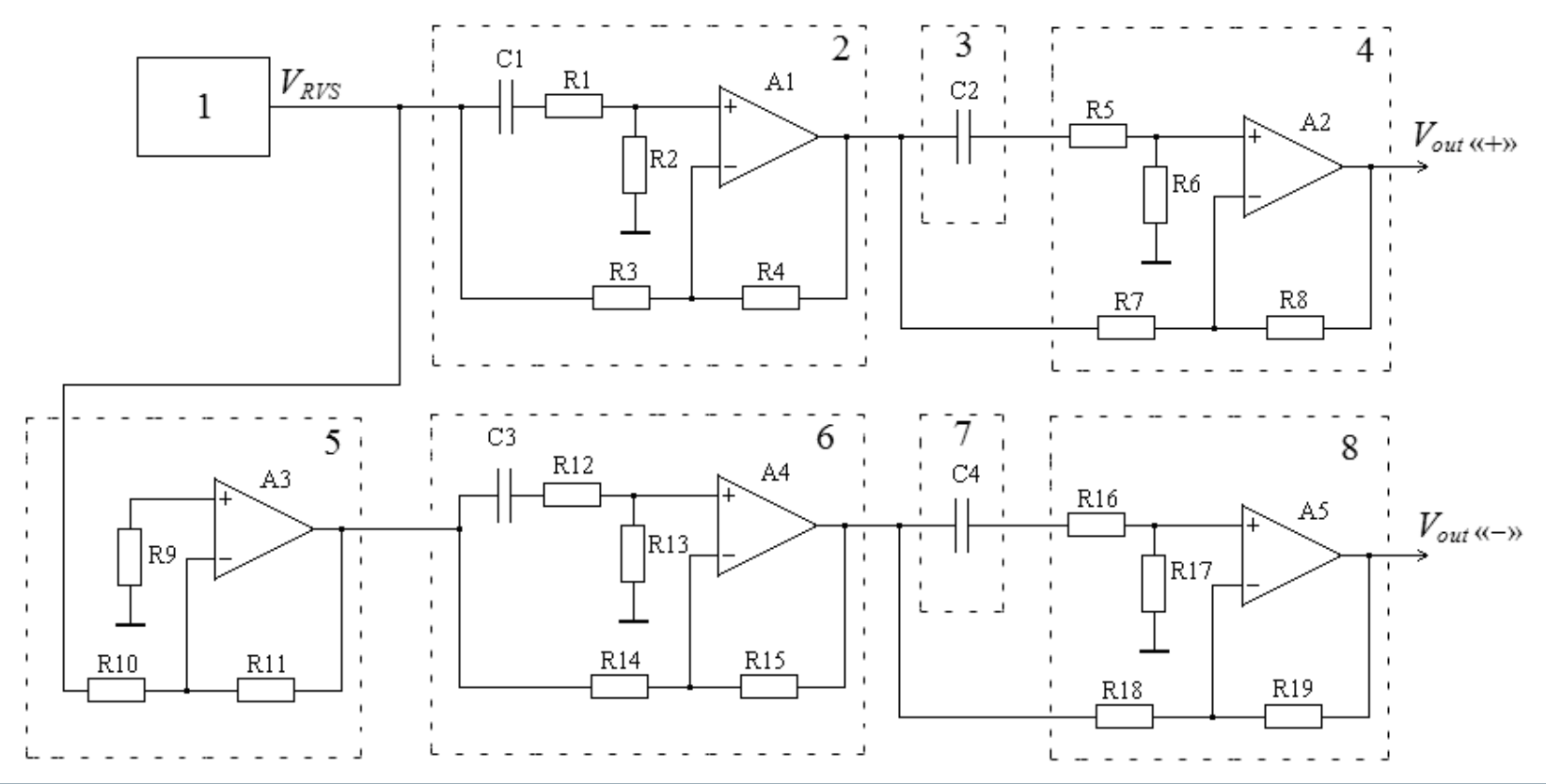

Fig. 4 Scheme for bipolar two-stage noise reduction

The scheme contains: RVS [1]; converters [2] and [6]; decoupling capacitors [3] and [7]; subtractors [4] and [8]; inverter [5]

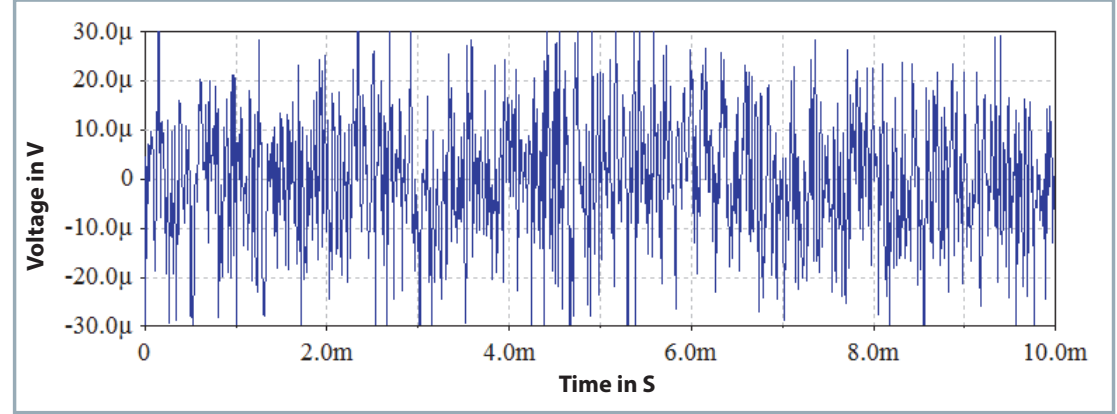

Fig. 5 The time diagram of RVS output noise voltage

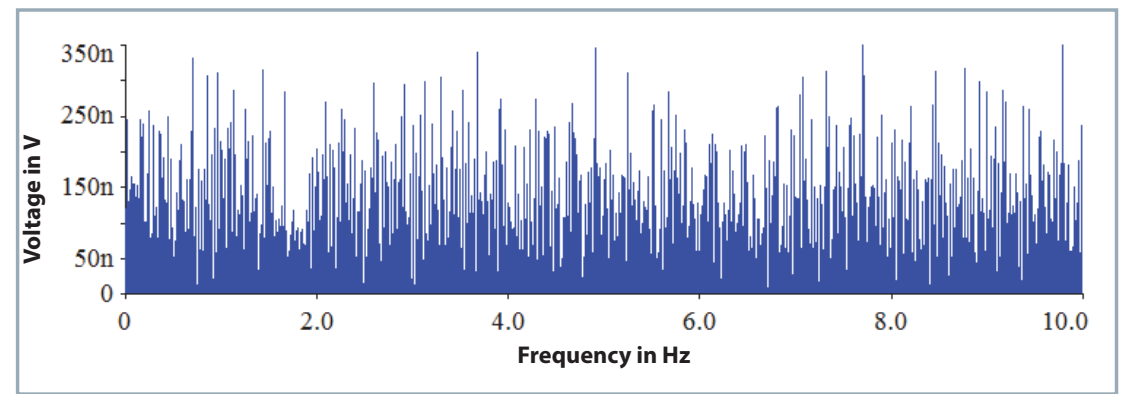

Fig. 6 The RVS output noise voltage spectrogram

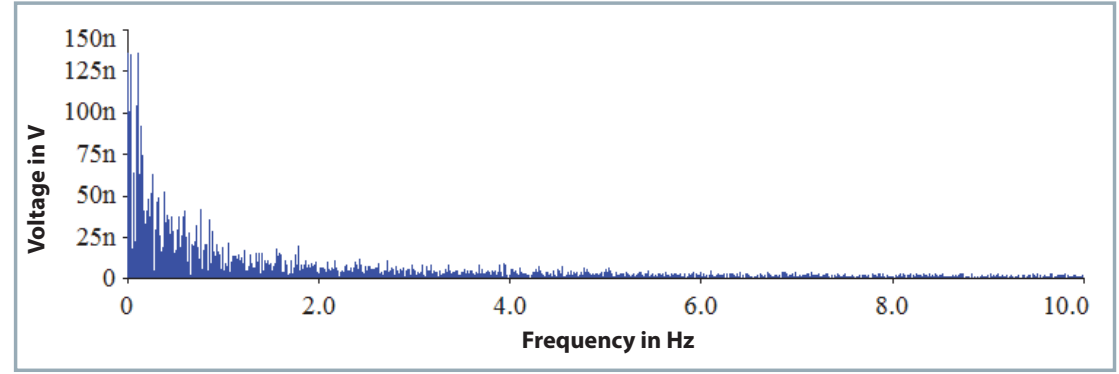

Fig. 7 The output noise voltage spectrogram of a single-stage noise reduction device; $C=1 \mu \mathrm{F}$
3. compensation of the noise (variable) component of non-inverted output voltage;

4. voltage inverting;

5. conversion of the inverted stabilized RVS output voltage spectrum;

6. separation of the noise (variable) component of the inverted transformed output voltage;

7. compensation of the noise (variable) component of the inverted output voltage.

The scheme of the device for forming of bipolar reference voltage with a two-stage noise reduction is shown in Fig. 4.

The circuit solutions for the implementation of blocks 2, 6 (Fig. 4) and block 2 (Fig. 2) in two-stage noise reduction devices, blocks 3, 7 (Fig. 4) and block 3 (Fig. 2), as well as blocks 4, 8 (Fig. 4) and block 4 (Fig. 2), are identical. The circuit solution for realization of block 5 (Fig. 4) and block 4 (Fig. 3) is also identical. Due to the identity of parameters of elements of circuit realization (Figs 2 and 4), the extent of the RVS noise reduction in both cases is also identical.

\section{Results and discussion}

The time diagram and spectrogram of the RVS output noise voltage for the $60 \mu \mathrm{V}$ peak-peak case are shown in Figs 5 and 6 , respectively. 
Table 4 Comparative assessment of the "output noise voltage" parameter for the RVS

\begin{tabular}{|c|c|c|c|c|c|}
\hline \multicolumn{2}{|l|}{ RVS } & $\begin{array}{l}\text { Output noise voltage } \\
\text { in } \mu \mathbf{V} \mathbf{p}-\mathbf{p}\end{array}$ & \multicolumn{2}{|l|}{ RVS } & $\begin{array}{l}\text { Output noise voltage } \\
\qquad \text { in } \mu \mathbf{V} \mathbf{p}-\mathbf{p}\end{array}$ \\
\hline \multicolumn{2}{|l|}{ MAX872 } & 60 & \multirow{2}{*}{\multicolumn{2}{|c|}{ ARD292 }} & \multirow{2}{*}{12} \\
\hline \multicolumn{2}{|l|}{ AD584 } & 50 & & & \\
\hline \multirow{3}{*}{$\begin{array}{l}\text { Single-stage noise } \\
\text { reduction based on } \\
\text { Op-amp-OP07C } \\
\text { and IVR }\end{array}$} & MAX872 & $51.2 \div 1.4$ & \multirow{3}{*}{$\begin{array}{l}\text { Two-stage noise } \\
\text { reduction based } \\
\text { on Op-amp- } \\
\text { OP07C and IVR }\end{array}$} & MAX872 & $43.2 \div 0.394$ \\
\hline & AD584 & $42.8 \div 1.2$ & & AD584 & $36 \div 0.392$ \\
\hline & ARD292 & $10.6 \div 0.6$ & & ARD292 & $9 \div 0.383$ \\
\hline
\end{tabular}

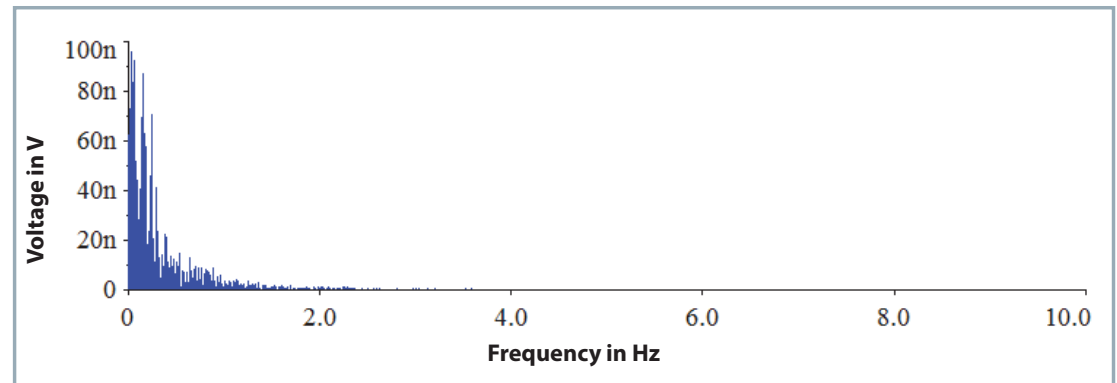

Fig. 8 The output noise voltage spectrogram of a two-stage noise reduction device; $C=0.82 \mu \mathrm{F}$

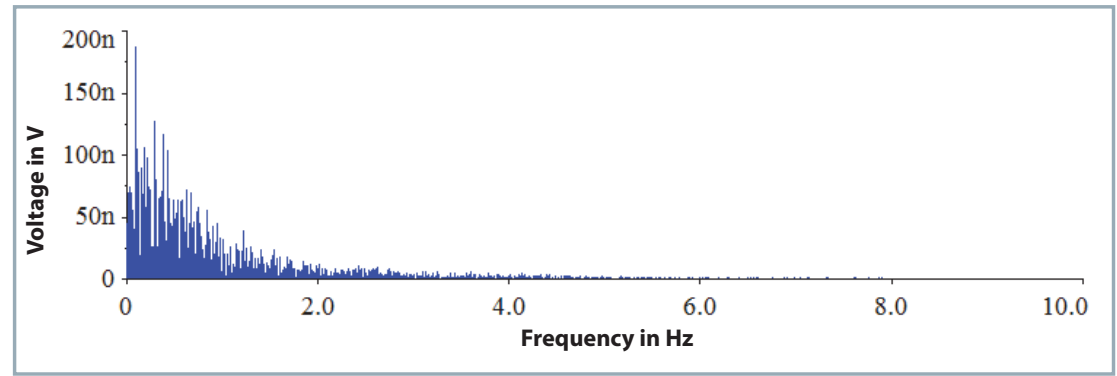

Fig. 9 The output noise voltage spectrogram of a two-stage noise reduction device; $C=0.25 \mu \mathrm{F}$

Figs 7-9 show the spectrograms of the output noise voltage of the noise reduction devices: a single-stage with $C=1 \mu \mathrm{F}$ (Fig. 7); a two-stage with $C=$ $0.82 \mu \mathrm{F}$ (Fig. 8); and a two-stage with $\mathrm{C}=0.25 \mu \mathrm{F}$ (Fig. 9).

The comparative assessment of the "output noise voltage" parameter in a frequency band $0.1 \div 10 \mathrm{~Hz}$ for typical IVSs and the aforementioned circuit solutions (Figs 1-4) is presented in Table 4.

\section{Conclusions}

1. The noise reduction methods of RVS presented in the paper, compared to standard noise reduction methods, such as:

- filtering the reference voltage (Morita, 2011);

- reducing the noise gain coefficient of the error amplifier (Morita, 2014) are characterized by higher indicators. Namely, the developed circuit solutions for lowering the output noise level of the reference voltage sources, both on the principles of a singlestage noise reduction, and on the principles of two-stage noise reduction, ensure a lowering of the RVS output noise level to the level of the intrinsic noise of operational amplifiers used in the developed devices.

2. Single-stage noise reduction is followed by a change of polarity of the stabilized voltage.

3. In case of two-stage noise reduction, relatively single-stage, the final outcome is dependent on the capacity size of the used capacitors.

\section{References} Device to generate reference voltage with reduced noise level. Stavropol State Agrarian University, Stavropol, Russia. (In
BONDAR, M. S. 2010a. Pat. 2422874 -
Russian: Ustrojstvo formirovaniya opornogo napryazheniya $s$ ponizhennym urovnem shumov).

BONDAR, M. S. 2010b. Pat. 2428736 - Shaping device of bipolar reference voltage with reduced noise level. Stavropol State Agrarian University, Stavropol, Russia. (In Russian: Ustrojstvo formirovaniya dvupolyarnogo opornogo napryazheniya s ponizhennym urovnem shumov).

CVIKLOVIČ, V. - OLEJÁR, M. - HRUBÝ, D. PALKOVÁ, Z. - LUKÁČ, O. - HLAVÁĆ, P. 2016. Navigation algorithm using fuzzy control method in mobile robotics. In Acta Technologica Agriculturae, vol. 19, no.1, pp. 19-23.

HOROWITZ, P. - HILL, W. 2015. The Art of Electronics. Cambridge University Press, 1125 pp. ISBN 978-0-521-37095-0.

LANTSOV, V. V. 1974. All-Union Scientific Research and Design Institute of Scientific Instrument Making, Reference voltage source, SU, A. s. 421002. (In Russian: Istochnik opornogo napryazheniya).

HSU, M. T. - LI, W. J. - CHIU, C. T. 2013. Design of low phase noise and low power modified current-reused VCOs for $10 \mathrm{GHz}$ applications. In Microelectronics Journal, vol. 44, pp. 145-151.

MORITA, G. 2011. Low dropout regulators Why the choice of bypass capacitor matters. In Analog Dialogue, vol. 45, no. 1, pp. 14-16. MORITA, G. 2014. Noise-reduction network for adjustable-output low-dropout regulators. In Analog Dialogue, vol. 48, no. 1, pp. 9-11.

NEIDORFF, R. A. - BEDFORD, N. H. 1989. US, Pat. 4,795,961 - Mass, Low-noise voltage reference. Unitrode Corporation, Lexington.

VOSTRUKHIN, A. V. 2013. Microcontroller reference voltage source. In Sensors \& Systems, vol. 2, pp. 37-39.

ZHAVORONKOVA, M. S. - BONDAR, S. N. 2012. Pat. 2496132 - Device to generate reference voltage with reduced noise. Stavropol State Agrarian University, Stavropol, Russia. (In Russian: Ustrojstvo formirovaniya opornogo napryazheniya s ponizhennym urovnem shumov).

ZHAVORONKOVA, M. S. - BONDAR, S. N. 2014. Pat. 2549509 - Shaping device of bipolar reference voltage with reduced noise level. Stavropol State Agrarian University, Stavropol, Russia. (In Russian: Ustrojstvo formirovaniya dvupolyarnogo opornogo napryazheniya s ponizhennym urovnem shumov). 